thiourea-treated ammocotes showed an absence of large vacuoles and the nuclei were basally placed (Fig. 2).

$$
\begin{gathered}
\text { Physiological Laboratory, } \\
\text { Trinity College, } \\
\text { Dublin. } \\
\text { June } 20 .
\end{gathered}
$$$$
\text { R. P. JONES }
$$

'Kennedy, T. H., Nature, 150, 233 (1942).

${ }^{2}$ MacKenzie, C. G., and MacKenzie, Julia B., Endocrin., 32, 185 (1943).

3 Astwood, E. B., J. Pharm. and Exp. Therap., 77, 79 (1943).

' Gordon, A. S., Goldsmith, E. D., and Charipper, H. A., Nature, 152,

'Lynn, W. G., and de Maire, A., Science, 103, 31 (1946).

\section{Stabilization of Penicillin-Salt Solutions with Sodium Citrate}

IN a recent paper ${ }^{1}$, I described the stabilizing effect of sodium citrate dissolved in physiological salt solution on the rate of destruction of sodium penicillin solutions by heat. Only very dilute concentrations of sodium penicillin ( $1-5$ units per ml.) were used.

The present communication deals with the effect obtained with higher concentrations ; 100, 1,000 and $3,000 \mathrm{u} . / \mathrm{ml}$. were tested and the optimal molar concentration of sodium citrate assessed.

Method. The agar-cup method as described in my previous paper was used. The average of at least three assays was compared with the standard curve constructed daily.

Results. (1) Solutions containing 100 and 1,000 u./ml. sodium penicillin (T.R.C. tabl. 392) were made up with sodium citrate solutions ranging from $M / 20$ to $M / 600$. The optimal effect was obtained with $M / 400$ at $p \mathrm{H} 5.6$ and solutions $(a)$ in $M / 400$ sodium citrate,

\begin{tabular}{|c|c|c|c|c|c|}
\hline \multirow{4}{*}{$\begin{array}{c}\text { at } 100^{\circ} \mathrm{C} . \\
\text { after } \\
15 \mathrm{~min} .\end{array}$} & \multicolumn{5}{|c|}{ Percentage of penicillin remaining } \\
\hline & \multicolumn{3}{|c|}{$100 \mathrm{u} . / \mathrm{ml}$} & \multicolumn{2}{|c|}{$1,000 \mathrm{u} . / \mathrm{ml}$. } \\
\hline & (a) & $(b)$ & (c) & (a) & (b) \\
\hline & 75 & 75 & & 100 & 100 \\
\hline 30 & 60 & 70 & 37 & 80 & \\
\hline 45 & 50 & 35 & & 80 & \\
\hline 60 & 25 & $12 \cdot 5$ & & 80 & 4 \\
\hline
\end{tabular}
(b) in distilled water adjusted to the same $p \mathrm{H}$ with phosphate, and $(c)$ in one test with distilled water $p H$ 4, were heated at $100^{\circ} \mathrm{C}$. The results were as follows:

It will be noted that the rate of destruction of sodium penicillin by heat was about the same in $(a)$ and $(b)$ up to 30 min., but higher in (c). After 45 and 60 min. the sodium citrate effect exceeds that of buffered distilled water.

(2) $3,000 \mathrm{u} . / \mathrm{ml}$. sodium penicillin T.R.C. 392 dissolved $(a)$ in $M / 1,000$ citrate solution $p H$ 6.4 and (b) in distilled water adjusted to $p \mathrm{H} 6.3$ with phosphate gave the following results after boiling:

\begin{tabular}{ccc} 
& \multicolumn{2}{c}{ Percentage remaining } \\
$\min$. & $(a)$ & $(b)$ \\
50 & 65 & 50 \\
75 & 48 & 40 \\
150 & 17 & 10
\end{tabular}

(3) Stabilization at room temperature. Ampoules were filled with penicillin salt solutions, then kept at $100^{\circ} \mathrm{C}$. for 15 minutes and afterwards at room temperature. The samples remained sterile as proved by several tests for sterility. The solutions contained : (a) $10,000 \mathrm{u} . / \mathrm{ml}$. sodium penicillin (The Distillers Co., Ltd., Liverpool) (915 units per mgm.) in $M / 500$ citrate solution, (b) the same in $M / 1,000$ citrate solution.

\begin{tabular}{ccc}
\multicolumn{3}{c}{ Percentage of penicillin remaining } \\
after days & $(a)$ & $(b)$ \\
21 & 80 & 80 \\
28 & 59 & 63 \\
35 & 41 & 48
\end{tabular}

A solution containing $1,000 \mathrm{u} . / \mathrm{ml}$. sodium penicillin T.R.C. 330 dissolved in distilled water lost 82 per cent of its potency after twenty-five days.

\section{HAHN}

106 Croft Road, Nuneaton.

${ }^{1}$ Lancet, i, 408 (1947).

\section{Microbiological Oxidation of Cholesterol with Azotobacter}

L. Mamoli and A. Vercellone ${ }^{1}$ were the first to work with the microbiological oxidation of sterols. They carried out investigations principally in a series of sex hormones, and with the aid of Coryne-bacteria, cultivated together with yeast, oxidized steroid alcohols to ketones. Recently, G. E. Turfitt ${ }^{2}$ found identical results with certain species of Proactinomyces.

At the beginning of our work we also used Proactinomyces; but we found that the species we isolated were capable only to a small degree of transforming steroid alcohols to ketones (in our experiments, principally cholesterol). We carried out our further investigations with a species of Azotobacter and observed the following results :

(1) The transformation of cholesterol to cholestenone was much more successful with Azotobacter than with our species of Proactinomyces.

(2) Besides the dehydration of the oxy-group, the Azotobacter also dehydrates within the sterol ring; thus from the reaction product we succeeded in isolating 7-dehydrocholesterol.

(3) Parallel to dehydration, a stronger oxidation of the cholesterol also took place, as after the process methylheptanone was also formed, from which the splitting off the side-chain could follow.

Our experiments were carried out in the following way. Cholesterol was dispersed in a rich synthetic culture medium of saccharose. The mixture was sterilized and added to the Azotobacter culture. A lively fermentation began, which lasted for three-four days, then gradually diminished. On the fourteenth day, after weak alkali hydrolysis, it was extracted with benzene. From the residue of the extract unchanged cholesterol was regained, then the methylheptanone was obtained by vapour distillation. The cholestenone was isolated through its semi-carbazone, and the 7-dehydrocholesterol by chromatographic adsorption.

Our experiments also support the hypothesis ${ }^{3}$ according to which 7-dehydrocholesterol in the organism results from an enzymatic action on cholesterol.

The determination of the Azotobacter species, as well as the identification of the product formed by the splitting off of the side-chain, are in hand. The experiments also aim at ascertaining the effect the Azotobacter species exercises on certain substances of the sterol series.

\section{J. HoRvÁTH}

A. KRÁMLI

Hungarian Biological Research Institute, Tihany. July 12.

${ }^{1}$ Mamoli and Vercellone, Ber. dtsch. chem. Ges., 70, 470, 2079 (1937); 71,1686 (1938).

'Turftt, Biochem. J., 38, 492 (1944); 40, 79 (1946).

schönheimer, Behring, Hummel and Schindel, Z. physiol. Chem., 182, $73(1930)$. 